\title{
Correspondence
}

\section{Clonidine is a better test of growth hormone deficiency}

Sir,

Fraser, Seth, and Brown ${ }^{1}$ claim by their title that, 'Clonidine is a better test of growth hormone deficiency than insulin hypoglycaemia.' This to me seems a rather important leap in logic from the data they present. The only point for diagnosing growth hormone deficiency is to select accurately those patients who may benefit from treatment with growth hormone. Therefore the best test of growth hormone deficiency, in terms of biochemical provocation tests, is the one which best discriminates between those children who will respond to treatment and those who won't. Simply obtaining higher values of growth hormone during the test are of little importance. The only way to clarify this point would be for all those children in whom there was a discrepancy between the clonidine and insulin tests to be submitted to a trial period of growth hormone treatment: using the response to this as the final arbiter would say which test was 'better'.

The authors imply this in their final paragraph but I think even with this caveat the title of their paper is misleading.

\section{A Preece Department of Growth and Development, Institute of Child Health, 30 Guilford Street, London WCIN $1 E H$}

Drs Fraser, Seth, and Brown comment:

We agree with Dr Preece that the choice of provocative test for growth hormone deficiency should ideally be based on therapeutic outcome, and we make this point in our discussion. The trial on patients with discrepant results that he suggests would be of interest but takes no account of the fact that criteria for abnormal and normal responses to the standard insulin tolerance test have not been defined in relation to therapeutic outcomes. Such a limited trial might therefore give a misleading impression of the diagnostic reliability of these tests.

Our claim that clonidine is a better test is based on the observation that there are patients who are manifestly not growth hormone deficient because they respond to clonidine, who do not respond to insulin. In addition the relative absence of troublesome side effects justifies the title chosen.

Sir,

We read with interest the article by Fraser et al. ${ }^{1}$ in which they confirmed the results previously reported by us in both prepubertal children ${ }^{2}$ and in adults ${ }^{3}$ showing a single oral dose of $0.15 \mathrm{mg} / \mathrm{m}^{2}$ of the alpha adrenergic agonist clonidine to be an effective growth hormone releasing agent and seemingly a better test for growth hormone deficiency than insulin induced hypoglycaemia.

In our previous studies we found that oral clonidine produced an appreciable suppression of cortisol and adrenocorticotrophic hormone when used at a dose of $0.15 \mathrm{mg} / \mathrm{m}^{2}$. This dose also induced a moderate amount of drowsiness and a drop in blood pressure. Further studies to elucidate whether a smaller single oral dose of clonidine can elicit an adequate growth hormone response, but at the same time diminish the drowsiness and the fall in cortisol and blood pressure seen with $0 \cdot 15 \mathrm{mg} / \mathrm{m}^{2}$ of clonidine, are now needed.

ROBERTO LANES Department of Pediatrics, North Shore University Hospital, 300 Community Drive, Manhasset, New York 11030,

References USA

1 Fraser NC, Seth J, Brown NS. Clonidine is a better tes for growth hormone deficiency than insulin hypo glycaemia. Arch Dis Child 1983;58:355-8.

2 Lanes R, Hurtado E. Oral clonidine: an effective growtt hormone-releasing agent in prepubertal subjects. $J$ Pediatr 1982;100:710-4.

${ }^{3}$ Lanes R, Herrera A, Palacios A, Moncada G. Decreased secretion of cortisol and ACTH after oral clonidine administration in normal adults. Metabolism 1983;32:568-70.

\section{Estimation of glomerular filtration rate from height/plasma creatinine ratio}

Sir,

Dr Guignard attributes to us views that we do not hold and which were not stated or implied in our paper. ${ }^{1}$ In view of the importance of this topic in general paediatric practice we would like to make a few comments on his letter. ${ }^{2}$

Firstly, we did not claim that an estimate of glomerular filtration rate (GFR) derived from height divided by plasma creatinine $\left(\mathrm{Ht} / \mathrm{P}_{\mathrm{cr}}\right)$ provides an 'ideal' measurement-only that it is at least as accurate as a 24 hour endogenous creatinine clearance, is easier to perform, and is of value as a screening test. We have ourselves, ${ }^{3}$ as have others before us, ${ }^{4}$ shown that a short creatinine clearance performed under supervision during a water diuresis is more accurate, but it is also a good deal more trouble. The same applies to various empirical permutations of urea and creatinine clearance that have been advocated successively and (in our view appropriately) forgotten over the years. ${ }^{5-7}$ 